\title{
La revolución informática y los procesos de lectura y escritura
}

\author{
EMILIA FERREIRO
}

$\mathrm{N}$

O HACEN FALTA muchos argumentos para convencer al público letrado de una vivencia cotidiana: la aparición y rápida diseminación de las computadoras de uso personal está transformando rápidamente nuestros modos de producir y leer textos. La expresión computer literacy esconde más de lo que explicita: una buena parte de la población, supuestamente letrada, resulta iletrada en relación a esta nueva tecnología.

Los que ya habían llegado a la galaxia Gutenberg deben reciclarse rápidamente. Pero ¿que haremos com los que ni siquiera llegaron al libro impreso? Com la aparición de las computadoras el abismo que ya separaba a los no alfabetizados de los alfabetizados se há ensanchado aún más: algunos ni siquiera llegaron a los periódicos, los libros y las bibliotecas, mientras otros corren detrás de hipertextos, correo electrónico y páginas virtuales de libros inexistentes.

¿Qué desafíos plantea esto para la educación pública? ¿Qué pasa com la gran mayoría de los maestros en la gran mayoría de los países periféricos (1)? En esos países (donde está la mayoría de la población mundial) el conjunto de los individuos que llamamos elementary teachers y el conjunto de aquéllos que han accedido a computer literacy tienen una intersección nula (o casi nula).

¿De qué alfabetización hablamos, en términos escolares? En las aulas escolares están ahora los ciudadanos del siglo XXI. ¿Los estamos preparando para la alfabetización del próximo siglo o para la del siglo XIX?

Para entender lo que está pasando ahora, y lo que puede pasar, hay que hacer un poco de historia, ya que lo que llamamos leer y escribir há ido cambiando en el transcurso de los siglos. Por razones de espacio nos limitaremos a la historia occidental (haciendo esporádicas referencias a lo que ocurría, mientras tanto, en lo que llamamos - de manera marcadamente egocéntrica - el oriente).

\section{Un poco de historia}

En un libro ya clásico, William Harris (2) trata de responder a la siguiente pregunta: ¿̨cuántas personas podían leer, y cuántas podían escribir en el mundo greco-romano? La pregunta no es banal, porque el origen del alfabeto se identificó, durante décadas, com la invención de una tecnología simple, eficiente y fácil de aprender, ligada desde sus orígenes a la ciencia y la filosofía contemporánea y a la idea de democracia occidental. En un denso libro de 383 páginas, Harris analiza 
todo tipo de evidencias históricas (desde la invención del alfabeto hasta el siglo V después de Cristo) y concluye que en ningún período hubo algo parecido a alfabetización masiva. Como máximo, estima que el 20\% de los hombres urbanos estaban alfabetizados en el 70 a.C. Todos los estudios históricos recientes muestran que ninguno de los pueblos antiguos que crearon y utilizaron escrituras (incluída mesoamérica) eran "sociedades alfabetizadas" según los estándares contemporáneos (que consisten en contar la cantidad de adultos mayores de 15 años que declaran saber leer y escribir y/o que han completado como mínimo cuatro años de escolaridad primaria o elemental). El alfabeto, de per si, no cambió esta situación.

Aquí hay varias historias que se superponen pero que no deben confundirse: por ejemplo, la historia del alfabeto no es lo mismo que la historia de los objetos portadores de escrituras y de sus significados sociales (monumentos públicos, tabletas de arcilla cocida, rollos de papiro o pergamino, dódices, libros etc.); la historia de los tipos de soportes materiales sobre los cuales se escribió y la historia de los instrumentos de escritura es totalamente distinta de la historia de los textos que fueron escritos (registros, cartas, genealogías, contratos, oráculos, decretos y leyes, obras religiosas, científicas o didácticas, épica y poesía); la historia de las prácticas de escritura, ya que se trata de dos actividades disociadas durante siglos; la historia de los libros que atribuímos, com razón, a un mismo autor no debe confundirse com la historia de la idea de autor, que es una idea muy moderna (3); la historia de las prácticas didácticas vinculadas com la alfabetización es solidaria pero diferente de la historia de las ideas sociales acerca del accesso a lo letrado; y aí siguiendo.

La disociación de funciones que hoy día nos parecen solidarias fue la norma durante los siglos pasados: el autor no era el ejecutor material de las marcas; los escribas no eran lectores autorizados; la escritura se exhibió durante siglos delante de poblaciones incapaces de leer lo exhibido, porque era un símbolo de poder entre otros (símbolo del detentor absoluto del poder, quien podía ser, a su vez, analfabeto).

Para los romanos de la época clásica, leer era devolver su voz al texto. La lectura en voz alta era una real interpretación del texto, producto de un cuidadoso trabajo previo. Por lo tanto, la lectura de un texto desconocido, colocado de improviso en las manos de um lector para que lo oralizara, se consideraba un absurdo. ¿Cómo podré leer lo que no entiendo?, argumenta un romano en esas circunstancias (4). El lector era un intérprete, en el mismo sentido en que ahora concebimos al intérprete de una partitura musical. Es obvio que un lector entrenado puede leer en silencio una partitura musical; pero entendemos que la partitura es un texto hecho para ser sonado, y no para dar lugar a lecturas silenciosas.

La comunidad de lectores era reducida y los textos también. Esos textos se copiaban y recopiaban, de preferencia en un tipo de escritura continua, que hoy día se nos antoja aberrante: sin espacios entre las palabras y sin signos de 
puntuación. La distinción de las palabras y la introducción de la puntuación quedaba a cargo del lector, era parte de sua tarea de intérprete $(5,6)$. Es importante señalar que la falta de separación entre palabras no era asunto de imposibilidad sino de preferencia: podían escribir de las dos maneras - como hoy día lo hacemos en cursiva o com caracteres separados - y ninguna de ellas se consideraba errónea, pero preferían la scriptio continua.

Siguieron prefiriendo la scriptio continua a pesar de las ambigüedades que ella podía generar. Los romanos sabían muy bien que la secuencia incultoloco podía dar lugar a dos interpretaciones contradictorias: inculto loco (lugar inculto) o bien in culto loco (en lugar culto). Y no siempre el contexto permitía decidir entre una o outra interpretación. Un gran lector como Plinio comete un gran error de interpretación, leyendo nada menos que a Aristóteles. En su Historia natural, Plinio habla de una rata marina que vive en el agua y pone sus huevos en la costa, por segmentar inadecuadamente el texto de Aristóteles (Historia de los animales), que habla de la tortuga marina: hdemus, emus= tortuga; mus = rata (4).

¿Por qué preferían los romanos de la época clásica la escritura sin espacios entre palabras? Hay varias razones: como dijimos, los lectores eran pocos y su entrenamiento suponía una educación especial; una actitud elitista estaría en la base de este deseo de dificultar el acceso al texto. Pero recientemente Parkes (6) há propuesto outra interpretación, mucho más interesante: los lectores preferían un texto no marcado, frente al cual la competencia del lector se manifestaba más plenamente. El efecto, un texto com separadores (incluida la puntuación) indica al lector qué es lo que deve procesar junto (porque forma parte de una misma unidad) y lo que debe procesar aparte. El texto no marcado expressa la confianza hacia el lector, hacia sua inteligencia para restituír la significación del original (7).

Muchos historiadores consideran que la separación sistemática entre palabras, junto com los procedimientos de mise en page a los que estamos acostumbrados, constituye la verdadera revolución en la historia de la lectura, antes de la imprenta occidental y superior en profundidad a los cambios producidos por el libro impreso. ¿Quiénes introdujeron la separación sistemática entre las palabras? No fueron los escribas de los grandes centros de cultura medieval. Fueron copistas irlandeses, hacia mediados del siglo VIII, en las fronteras geográficas de la cristiandad medieval. Y esa invención tardó siglos en imponerse.

\section{Un poco de futuro}

Tenemos tendencia a imaginar que cualquier tecnología introduce cambios psicológicos sustanciales. Sin embargo, no siempre es así: una serie de cambios que durante décadas fueron atribuídos a la imprenta, según ahora sabemos, fueron difundidos por la imprenta pero tuvieron su origen en cambios mucho más sutiles que le precedieron, y que no fueron cambios propiamente tecnológicos: los cambios que dieron lugar a esa "gramática de la legibilidad" (según la feliz expresión de Parkes), a esa visión de la textualidad que hoy día nos resulta familiar 
(un texto com título y autor claramente visible al comienzo, com páginas numeradas, com índice, com división en capítulos, secciones y parágrafos, com un ordenamiento numérico o alfabético, com letras ampliadas para indicar comienzo o titulación, com una puntuación que ayuda al lector a encontrar los límites externos e internos de cierta parte del discurso argumentativo) (8).

La tecnologia que permitió la lectura silenciosa, la búsqueda rápida y la citación es anterior a la imprenta. Pero la imprenta introdujo un cambio total y completo en un aspecto crucial: la idea de copia de un mismo texto. Antes de la imprenta, la idea de ejemplares idénticos del mismo texto era un ideal nunca alcanzado. Después de la imprenta, se convirtió en una banalidad.

El autor del texto, que ya se había convertido en autor material de las marcas (el productor del manuscrito) tuvo que disputar su autoría com la de los editores. En no pocos casos los editores - personas cultas y no simplemente comerciantes - tenían su propia idea de la ortografía y la puntuación y los autores no siempre tuvieron éxito en lograr que la versión editada correspondiera a su próprio manuscrito (com los editing actuales suele pasar algo similar).

La máquina de escribir (mecánica o eléctrica) permitió una variación en la idea del manuscrito: el susodicho manuscrito (= escrito de propia mano) podía ser mecanografiado (= grafado por medios mecánicos). La marca personal del autor - su propia letra - quedava limitada a la firma. Pero la ausencia de lo grafado a mano no impedía la manifestación de una marca personal menos visible pero más profunda: su estilo como escritor.

La computadora permite una nueva aglutinación: el autor de las marcas puede ser su propio editor. En el teclado tiene a su disposición una gran cantidad de tipos de caracteres. Antes tenía cuatro opciones: mayúscula/minúscula, subrayado o no. Ahora puede variar el tamaño y el tipo de los caracteres, puede insertar dibujos o recuadros... y puede enviar directamente su diskette a la imprenta. En otras palabras: el autor intelectual y el autor material se completan ahora com el editor material. La posición frente a lo que escribimos há cambiado. La posibilidad de transponer, a voluntad, párrafos enteros, o de traer hacia la pantalla partes de otros textos, da al productor grados de libertad antes inimaginables (digamos, de paso, que toda una especialidad, vinculada com la crítica textual moderna, está amenazada de extinción: quienes se ocupan del análisis de los manuscritos de autor - y su comparación com las versiones impresas corren el serio riesgo de no contar más com la materia prima de su quehacer profesional. Los autores modernos ya no dejan traza de sus correcciones sobre el papel) (9).

Lo innegable es que la pantalla se há convertido en una superficie priveligiada. ¿Es la existencia de la pantalla - de TV o de computadora - lo realmente innovador? Com el auge de la TV y la posibilidad de transmisión instantánea de imágenes a distancia, se habló de la muerte de la escritura, del reemplazo de lo escrito por la imagen directa de los hechos. En términos 
educativos, se hicieron fabulosas proyecciones: los cursos a distancia, por TV, reemplazarían al cara a cara tradicional. Pero la computadora personal, en su uso más banal de instrumento sofisticado para escribir e imprimir, tanto como en sus usos más recientes de convertir al usuario en un navegante en redes informáticas, reintrodujo el poder de la escritura, aunque rápidamente vinculado al de la imagen, en un nuevo tipo de interacción.

Es por ahora pura especulación el imaginar cuáles de los aspectos de las nuevas tecnologías tendrán el mayor impacto. Lo que es imposible creer es que las autopistas informáticas y la proliferación de redes estén abriendo realmente el camino hacia la democracia. Ya nos dijeron durante décadas que el alfabeto era la escritura más democrática de todas, y hoy sabemos que se trataba de una visión puramente ideológica de la historia.

En una conferencia reciente, un sociólogo atento a los cambios en el comportamiento lector (9) propuso que el verdadero instrumento revolucionador de las prácticas no es la pantalla sino el aparatito de control remoto. Este aparatito há creado una "cultura de la interrupción y de la impaciencia" que conduce hacia la fragmentación del texto. Yuxtaponer, privilegiar los "tiempos fuertes" en detrimento de las transiciones, cambiar continuamente antes de tener el tiempo de analizar; todo ello constituye un conjunto de comportamientos de la nueva generación (la que nació conviviendo com el televisor) que se transladan com la mayor facilidad a la outra pantalla de la vida contemporánea: la de la computadora. Podemos suponer, com fundamento, que el modo de actuar frente a estas dos pantallas puede afectar la relación com lo impreso, no sólo en frecuencia de uso sino, lo que es más importante, en el modo de relación com lo impresso.. "La manera de circular entre las imágenes (y no sólo en la imagen) cambia la manera de circular en el texto", dice Barbier Bouvet. Y yo agregaría: cambia también la manera de circular entre los textos.

\section{¿Y la escuela qué?}

La escuela, siempre depositaria de cambios que ocurren fuera de sus fronteras, debe cuando menos tomar conciencia del desfasaje entre lo que enseña y lo que se practica fuera de sus fronteras. No es posible que siga privilegiando la copia - oficio de monjes medievales - como prototipo de escritura, en la época de Xerox \& Co. No es posible que siga privilegiando la lectura en voz alta de textos desconocidos (mera oralización com escasa comprensión) en la era de la lectura veloz y de la necesidad de aprender a elegir la información pertinente dentro del flujo de mensajes impresos que llegan de forma desordenada, caótica e invasora.

No es posible que aún se instauren debates acalorados pro y contra las virtudes/inconvenientes de tal o cual tipo de grafías (continuas o discontinuas) en una época en que lo único urgente es introducir a los estudiantes al teclado. El teclado de una computadora y el de una máquina de escribir no há sido aún 
percibida como un instrumento didáctico por la institución escolar (10). En un trabajo reciente sobre condiciones de alfabetización en medio rural (11) pusimos de manifiesto la posibilidad y la utilidad de introducir viejas máquinas de escribir mecánicas en escuelas de comunidades rurales aisladas. La posibilidad: esas viejas máquinas mecánicas se encuentran en depósitos de instituciones públicas y privadas que se han reciclado hacia máquinas eléctricas o, más recientemente, hacia computadoras personales. Basta com la voluntad de recuperarlas y una mínima inversión para repararlas (12). La utilidad: los niños pueden iniciar sus primeros intentos por escribir com todos los medios materiales a su disposición. La máquina de escribir es uno de ellos, que no compite com el lápiz sino que es complementario. Pero escribir a máquina tiene un prestigio y una nitidez que la escritura de un escritor principiante no logra. Mas aún: en un país donde todavía los escribientes públicos gozan de una aureola de prestigio ligada a una supuesta tecnicidad del oficio, poner a disposición de niños de 6 años (y de culquier edad) ese instrumento es contribuir a desmistificar ese oficio y, simultáneamente, es contribuir a dar acceso al teclado (medio moderno por excelencia de producción de escrituras... y de acceso al mercado laboral) (13). No sólo eso: cuando un texto há sido producido a mano, há sido discutido en grupo y luego se lo pasa a máquina, surgen preguntas y discusiones sobre problemas ortográficos que dificilmente surgen en otros contextos. El texto pasado a máquina adquiere, por su misma naturaleza, un carácter público, y entonces se justifican preguntas sobre si va junto o separado, si va com o sin hache, si lleva mayúscula, y otras semejantes (el rol de la máquina de escribir en el surgimiento de problematizaciones ortográficas no es nada despreciable, ya que la escuela nunca há encontrado situaciones funcionales para hacer surgir la duda ortográfica).

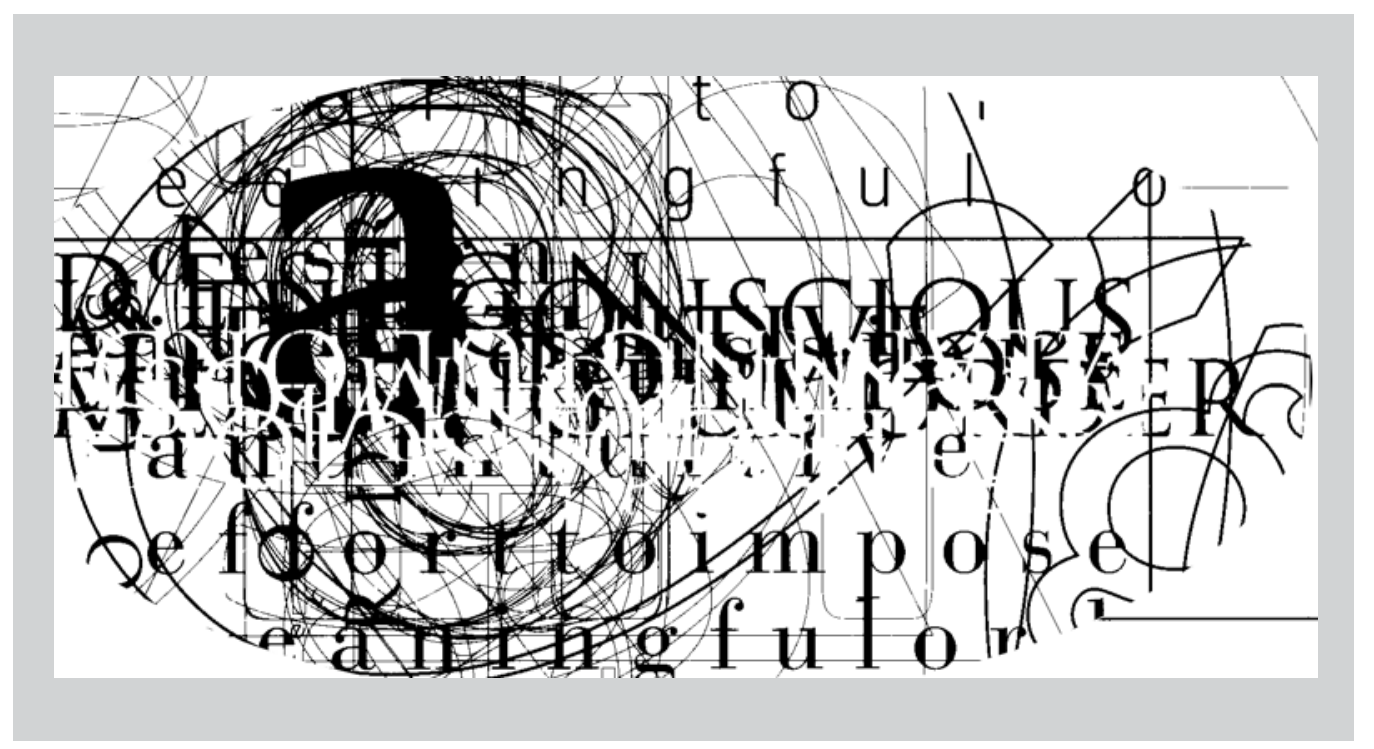

"El autor del las marcas puede ser su propio editor" 
¿De qué lectura estamos hablando en el contexto escolar? Aprender a obtener información de distintas fuentes, valorarlas y dudar de su veracidad no es - admitámoslo - un ejercicio escolar frecuente. Hablamos mucho del placer de la lectura, placer que muchos docentes nunca han experimentado de primera mano. Los hijos de padres alfabetizados y lectores suelen tener la primera experiencia de ese placer (que, en realidad, es menos placer que problematización, ingreso a lo deseable desconocido) en edades muy tempranas: a los dos o tres años, cuando les leyeron por primera vez un libro y luego pidieron insistentemente que se los volvieran a leer (14). Pero la mayoría de los niños que asisten a las escuelas públicas no han tenido esa experiencia, y tampoco la tendrán al ingresar a la escuela. Mal que les pese, parece que la maestra no está allí para leer a nadie, sino para enseñar la mecánica de la lectura.

Lo sorprendente e inquietante es que, al mismo tiempo en que aumentan los requerimientos de lectura para la población demandante de empleos, la investigación pone de manifiesto que aprender a leer no es simplesmente una cuestión técnica. Durante décadas nos acostumbramos a pensar que la escritura es una invención puramente técnica, que permite pasar del registro audible al visual, transformando la temporalidad en simultaneidad, convirtiendo el orden secuencial oral en un orden visual lineal. Consecuentemente, aprender a leer no sería más que aprender a asociar formas gráficas a unidades fónicas que están inmediatamente a disposición del hablante (o que este podría reconocer gracias a outro entrenamiento técnico complementario y relativamente sencillo).

Ahora sabemos que esta visión tradicional no sólo sobre-simplifica el problema sino que lo deforma: esas asociaciones sonoro-visivas y gráfico-auditivas son apenas uno de los aspectos (y no el más relevante) del ingreso a la cultura letrada. Aprender a leer y escribir es mucho más que eso: es construír un nuevo objeto conceptual (la lengua escrita) y entrar en outro tipo de intercambios lingüísticos y culturales (15).

\section{A modo de conclusion provisional}

No se trata de reinstaurar el ya viejo debate entre TV versus pizarrón; o sea, no se trata de lamentar las horas que los niños pasan frente a una TV que poco o nada tiene de interactiva y mucho de consumismo pasivo. Tampouco se trata de idealizar las horas pasadas frente al pizarrón, como si fueran, por definición, más provechosas que las otras.

De lo que se trata es de estar alertas a los cambios que están ocurriendo que puedem involucrar cambios profundos en la relación de los ya letrados com los textos, y en el modo en que se alfabeticen las nuovas generaciones - y de reconocer que los cambios necesarios a nivel educativo son muy drásticos, precisamente porque ya, ahora, la escuela pública está tremendamente desactualizada. Si la tecnología informática llegara a servir, como circunstancia disparadora, para repensar lo que ocurre en la escuela, bienvenida sea. 
Notas

1 Esos mismos países que antes eran subdesarrollados, que después fueron en vías de desarrolo, pero como nunca llegaron al desarrollo prometido parecía mejor hablar de ellos como tercer mundo, pero ahora no está tan claro dónde está el segundo mundo y de nuevo no se sabe cómo llamarlos, ya que la escueta denominación Sur ofende, en su uso político, a la Geografía.

2 W. Harris. Ancient literacy, Harvard University Press, 1989.

3 R. Chartier. Libros, lecturas y lectores en la edad moderna. Barcelona, Alianza Universidad, 1992.

4 F. Desbordes. Idées romaines sur l'écriture. Presses Universitaires de Lille, 1990. Traducción: Concepciones sobre la escritura en la antigüedad romana. Barcelona, Gedisa, 1995.

5 P. Saenger. The separation of words and the physiology of reading. In: D. Olson \& N. Torrance (eds.) Literacy and orality. Cambridge University Press, 1991. Traducción: Cultura escrita y oralidad. Barcelona, Gedisa, 1995.

6 M. Parkes. Pause and effect. An introduction to the history of punctuation in te West. Hants, UK, Scolar Press, 1992.

7 En esse sentido, la multiplicación de marcas de los modernos procedimientos de edición expresan una desconfianza creciente hacia el lector. Véanse, por ejemplo, todos los recursos que utilizan los libros y revista didáticas (recuadros, colores, flechas etc.) para facilitar la lectura (o sea, para que un lector en el cual no se tiene confianza encuentre ya agrupado y senalado lo que debe leer prioritariamente, como un único bloque).

8 Varios de esos recursos textuales que el occidente tardó siglos en desarrollar eran ya bien conocidos por los impresores chinos, alrededor del siglo V y VI. Eso es lo que demuestra la extraordinaria colección de libros impresos hallados en el valle de Turfan (región que corresponde actualmente al Turkestán chino). T. Carter, The invention of printing in China. New York, Columbia University Press, 1925; edición revisada, 1931.

9 J.F. Barbier Bouvet. Lire la page comme une image. In: A. Bentolila (comp.) Parole, ecrit, image. Paris, Nathan, 1993, p. 225. I. Castro. La mano que habla al cerebro, Substratum, II, 65, 1995.

10 Algo diferente ocurrió com las calculadoras de bolsillo, gracias a lo reducido de su tamaño y la caída acelerada de sus precios de compra. Hoy día es habitual ver trabajos en didáctica de las matemáticas que toman en cuenta a esas calculadoras como instrumentos didácticos. Hace varios años hicimos el elogio de las calculadoras como instrumentos que permitían instaurar la racionalidad del cálculo aproximado en el contexto escolar, veáse E. Ferreiro, Procesos de alfabetización. La alfabetización en proceso, cap. II. Buenos Aires, Centro Editor de América Latina, 1986.

11 E. Ferreiro, B. Rodríguez et al. Las condiciones de alfabetización en medio rural. Cinvestav \& Kellogg Foundation, 1994. 
12 Por ahora son viejas pero no antigüas. Eso equivale a decir que son objeto de desecho y no antigüedades. Cuando se conviertan en antigüedades ya no será posible rescatarlas a costo nulo o casi nulo.

13 Lo que decimos se aplica, aún com mayor razón, a la educación de adultos.

14 E. Ferreiro. Acerca de la necesaria coordinación entre semejanzas y diferencias. In: J. Castorina, E. Ferreiro, D. Lerner \& M. Kohl. Piaget-Vigotsky: contribuciones para replantear el debate. Buenos Aires, Paidos, 1996.

15 Imposible desarrollar lo que corresponde a veinte años de trabajo sobre la psicogénesis de la lengua escrita. Veáse, por ejemplo, E. Ferreiro \& A. Teberosky. Los sistemas de escritura en el desarrollo del niño. México, Siglo XXI, 1979, 12ª edición en 1991; E. Ferreiro. La complejidad conceptual de la escritura. In: L.F. Lara \& F. Garrido (comps.) Escritura y alfabetización. México, Ed. Del Ermitaño, 1986; E. Ferreiro, L'écriture avant la lettre. In: H. Sinclair (comp.). La production de notations chez le jeune enfant. Paris, University de France, 1988; E. Ferreiro. Psychological and epistemological problems on written representation of language. In: M. Carretero, M. Pope, R. Simons \& J. Pozo (eds.). Learning and instruction. European research in an international context, v. 3. Oxford, Pergamon Press, 1991.

Emilia Ferreiro formou-se em Psicologia Social na Universidade de Buenos Aires e obteve seu doutorado na Universidade de Genebra, Suíça, sob a orientação de Jean Piaget. É professora titular do Centro de Pesquisa e Estudos Avançados do Instituto Politécnico Nacional do México, desde 1979. Atua como professora visitante e conferencista junto às mais importantes universidade do mundo, além de assessorar projetos de alfabetização e ensino em diversos países da América Latina, incluindo o Brasil. Tem oito livros publicados, além de capítulos em livros e artigos em revistas.

Texto publicado na revista Avance y Perspectiva - Órgano de difusión del Centro de Investigación y de Estudios Avanzados del I.P.N., México - v. 15, set./out. 1996.

No dia 30 de outubro de 1996, a autora fez a palestra A diversidade: um tema para a pesquisa psicolingüistica e para repensar a educação do próximo milênio, no Auditório da Escola de Aplicação da Faculdade de Educação da USP, dentro do Ciclo Comemorativo do décimo aniversário do IEA-USP. 